\title{
STUMBLING BLOCKS IN POPULATION CONTROL.
}

1. MBBS, FRCOG (London) Professor Gynae/Obs Akhtar Saeed Medical and Dental College, Lahore, Pakistan

2. MBBS, MCPS, FCPS

Associate Professor Gynae/Obs Akhtar Saeed Medical and Dental College, Lahore, Pakistan

3. MBBS, MCPS, FCPS Assistant Professor Gynae/Obs Akhtar Saeed Medical and Dental College, Lahore, Pakistan.

4. MBBS, FCPS

Senior Registrar Gynae/Obs Akhtar Saeed Medical and Dental College, Lahore, Pakistan

5. MBBS, SBOG

Senior Registrar Gynae/Obs Akhtar Saeed Medical and Dental College, Lahore, Pakistan.

6. MBBS, FCPS

Professor of Gynae/Obs Akhtar Saeed Medical and

Dental College, Lahore, Pakistan.

Correspondence Address:

Dr. Drakhshan Nauman

House \# 488, Pak Block

Allama lqbal Town, Lahore, Pakistan. drdrakhshan@yahoo.com

Article received on:

14/07/2020

Accepted for publication:

21/09/2020

\section{INTRODUCTION}

Pakistan is the $6^{\text {th }}$ most populous country in the world and according to Pakistan Bureau of Statistics 2017, population of Pakistan is 220 million. Pakistan faced massive population explosion since its existence. Our population increased from 33million in 1947 to 207 million in 2017. ${ }^{1}$ Pakistan is also second highest densely populated country in the world after India.

In the year 2000, United Nations worked on Millennium Development Goals (MDGs) and defined 8 goals to be achieved by 2015. Goal no 5 was to improve maternal and reproductive health., ${ }^{2,3}$ In 2015, United Nations worked on Sutainable Development Goals (SDGs) and it also included an essential component of family planning. ${ }^{4}$

\begin{abstract}
Naheed Jmal Faruqi ${ }^{1}$, Drakhshan Nauman², Nadia Saif ${ }^{3}$, Shereen Sukhan ${ }^{4}$, Faiza Saghir ${ }^{5}$,
\end{abstract} Fariha Farooq ${ }^{6}$

(o. Objectives: This study was conducted to determine frequency of contraceptive Setting: Department of Obstetrics and Gynecology Farooq Hospital, Westwood Branch, Lahore. Period: From $1^{\text {st }}$ July 2019 to $31^{\text {st }}$ December 2019. Material \& Method: All married between 18-40 years of age,having at least one child, presenting to gynae outdoor, ing version 16. Results: Out of total 408 participants, $48.3 \%$ were in age range of 21-30 years and $86.5 \%$ were having parity of $\geq 2.47 .5 \%$ participants were illetrate and $52.5 \%$ were having erent level of education. 53\% participants were not using any contraception and only $47 \%$ (32. common reasons among nonusers were lack of knowledge $(30.5 \%)$ and fear of side effects (21.7\%). Least common reasons were myths and false beliefs (8.8\%). Common complications users were menstrual irregularity (29.6\%),vaginal discharge (12\%) and failure of of government family planning policies and motivation of couples through media and health

Key words: $\quad$ Contraception Prevalence Rate, Family Planning, Millennium Development Goals (MDGs), Sutainable Development Goals (SDGs). locks in population control. Professional Med J 2020; 27(10):2260-2265. DOI: $10.29309 / T P M J / 2020.27 .10 .5575$

The history of family planning in Pakistan is complex. The family planning programme was first initiated in 1953 in private sector. Late, in 1966 it was made part of state policy. Family planning was declared as independent ministry in 1990. Contraception prevalence rate of Pakistan was $5 \%$ in 1960 and $12 \%$ in 1990 . As results were not encouraging so family planning programmme was upgraded with public private partnership and involvement of lady health workers (LHWs) and it lead to better performance and CPR increased to $30 \%$ in $2000 .{ }^{5}$ CPR remained static afterwards.

Worldwide 214 million women of reproductive age have unmet need for contraception. ${ }^{6}$ Globally contraceptive prevalence rate is $64 \%$ and in developing country it is as low as $40 \%$. So poor countries need another 120 million users by 2020 
to attain health related Millennium Development Goals (MDGs). ${ }^{7}$

Currently total fertility rate in Pakistan is 3.6 children / women and CPR is $34.2 \%$ according to 2018 report. This CPR is lowest in South East Asian countries, except for Afghanistan. ${ }^{8}$ So, Pakistan has to go a long way to improve CPR.

There are multiple benefits of family planning including birth spacing, avoiding unwanted pregnancies and hence reducing illegal and unsafe abortions and deciding family size. Unintended pregnancies and termination by untrained personnel in poor environment is a major contributory factor to maternal deaths and malnutrition in mothers and children. Poverty, illetracy, poor health services especially in rural areas where majority reside are the main issues waiting to be addressed. Other benefits of family planning are prevention of anemia in women, improved nutrition of mother and children, prevention of STDs and reduction of maternal and perinatal mortality thus leading to economic development of the country.

Many factors influence use and preference of contraceptive methods. These include socioeconomic status, awareness and access to contraceptive services, education of the couple, religious beliefs and demographic features. Other factors include availability, cost and side effects of contraceptives, knowledge about various methods, media support, gender preference of couple, and most importantantly support from husband and in- laws. ${ }^{10,11}$

The aim of study was to look into frequency of contraceptive use, side effects of various methods and reason for not practicing contraception among participants attending gynaecology outdoor of our hospital.

\section{MATERIAL \& METHODS}

The study is cross sectional study and conducted in Department of Gynae/Obs Farooq Hospital, Westwood Branch, Lahore from $1^{\text {st }}$ July 2019 to $31^{\text {st }}$ December 2019. Total 408 patients presenting to gynae outpatient department of our hospital during study period were included in the study. Informed consent from all patients taken before enrolment in study.Ethical approval obtained from hospital administration.

Non probability convenient sampling done to collect data.All married women between 18-45 years of age and having at least one child were included in the study. Those women who already had sterilistaion and those women not living with their husband for more than 6 months were excluded from study.All women were interviewed in gynae outdoor and all informations entered on a proforma.

Data analysis done by using SPSS version 16. Age and parity expressed as mean and standard deviation. Education, contraceptive choices,factors affecting use of contraception and complications of various contraceptive methods were expressed as frequency and percentages.

\section{RESULTS}

Demographic variables are shown in Table-l. Majority of women were in age range of 21-30 years. ( $n=197,48.3 \%)$ and $86.5 \%$ women were having parity of $\geq 2$.

Education of female participants is shown in Table-II. $47.5 \%$ women were illetrate while $52.5 \%$ were having different levels of education.

Figure-1 is showing various contraceptive methods used by participants. Out of total 408 participants, 216 (53\%) were not using any form of contraception. Only 192 (47\%) were using contraception. Most preferred choice among users were interval intrauterine contraceptive device (IUCD) ( $n=62,32.3 \%$ ) and Barrier methods $(n=58,30.2 \%)$. Least commonly used method was Implanon $(n=2,1.04 \%)$.

Reasons for not practising contraception among nonusers $(n=216,53 \%)$ were shown in TableIII. Most common reason turned out to be lack of knowledge $(n=66,30.5 \%)$ and least common reason was myths and false beliefs $(n=19,8.8 \%)$

Side effects of various methods are shown 
in Table-IV. Most common side effect was menstrual irregularity $(n=57,29.6 \%)$, vaginal discharge $(n=23,12 \%)$ and failure of method leading to conception $(n=15,7.8 \%)$.

\begin{tabular}{|c|c|c|}
\hline Variables & Number (n) & Percentage (\%) \\
\hline \multicolumn{3}{|l|}{ Age in years } \\
\hline $18-20$ years & 62 & 15.2 \\
\hline $21-30$ years & 197 & 48.3 \\
\hline $31-40$ years & 149 & 36.5 \\
\hline \multicolumn{3}{|l|}{ Parity } \\
\hline Para 1 & 55 & 13.5 \\
\hline Para 2-4 & 177 & 43.4 \\
\hline Para 5-6 & 84 & 20.6 \\
\hline Para $\geq 6$ & 92 & 22.5 \\
\hline \multicolumn{3}{|c|}{ Table-I. Demographics of participants $(n=408)$} \\
\hline Literacy Status & Number (n) & Percentage (\%) \\
\hline Illetrate & 194 & 47.5 \\
\hline Primary & 38 & 9.3 \\
\hline Middle & 22 & 5.4 \\
\hline Matric & 56 & 13.7 \\
\hline Intermediate & 34 & 8.3 \\
\hline Graduation & 36 & 8.8 \\
\hline Postgraduation & 28 & 6.8 \\
\hline
\end{tabular}

Table-II. Educational status of participants $(n=408)$

\begin{tabular}{|c|c|c|c|c|}
\hline \multicolumn{2}{|l|}{ Reasons } & \multicolumn{2}{|c|}{ Number (n) } & $\begin{array}{l}\text { Percentage } \\
(\%)\end{array}$ \\
\hline \multicolumn{2}{|l|}{ Lack of knowledge } & \multicolumn{2}{|l|}{66} & 30.5 \\
\hline \multicolumn{2}{|l|}{ Lack of access } & \multicolumn{2}{|l|}{21} & 9.7 \\
\hline \multicolumn{2}{|c|}{ Non cooperation by family } & \multicolumn{2}{|l|}{43} & 20 \\
\hline \multicolumn{2}{|l|}{ Myths and false belief } & \multicolumn{2}{|l|}{19} & 8.8 \\
\hline \multicolumn{2}{|l|}{ Religious constraints } & \multicolumn{2}{|l|}{20} & 9.3 \\
\hline \multicolumn{2}{|l|}{ Fear of side effects } & \multicolumn{2}{|l|}{47} & 21.7 \\
\hline \multicolumn{5}{|c|}{ Table-III. Reasons for not using contraception $(n=216)$} \\
\hline Side Effects & \multicolumn{2}{|c|}{ Number (n) } & \multicolumn{2}{|c|}{ Percentage (\%) } \\
\hline Menstrual irregularity & \multicolumn{2}{|r|}{57} & & $29.6 \%$ \\
\hline Vaginal discharge & \multicolumn{2}{|r|}{23} & & $12 \%$ \\
\hline Failure of method & \multicolumn{2}{|r|}{15} & & $7.8 \%$ \\
\hline \multicolumn{5}{|c|}{$\begin{array}{c}\text { Table-IV. Side effects of various contraceptives } \\
\text { among users }(n=192)\end{array}$} \\
\hline
\end{tabular}

\section{Figure-1. Contraceptive choices among users $(n=192)$}

\section{DISCUSSION}

Good reproductive health and effective family planning services is a key factor for strong economy of a nation.Contraception prevalence rate of Pakistan is very low (34.2\%) according to 2018 report. $^{8}$ and there is disparity of contraceptive practices among rural and urban areas. This study was conducted in a tertiary care teaching hospital to assess frequency of women using different methods of contraceptions, side effects of various methods and reasons for not using any method.

Majority of women seeking contraception in our study were in age range of 21-30 years (48.3\%), and it is considered peak age range of pregnancy in Pakistan. Similar results depicted in study by Qadir. $\mathrm{S}^{12}$ in 2018 where $49 \%$ women were in age range of $15-30$ years and Sohail. $\mathrm{N}^{13}$ in 2015 where $52.4 \%$ women were in age range of 21-30 years. Contrasting results shown by an Indian study in 2018 where $81.2 \%$ women seeking contraception were in age range of 21-30 years. ${ }^{9}$

In our study, $86.5 \%$ women seeking contraception were having parity of $\geq 2$. Similar results shown by other studies. ${ }^{9,13}$ However contrasting results were shown by study in Nepal in 2013 where only $11.2 \%$ women were having parity of $\geq 2 .{ }^{14}$

The education status of women even in rural area is unsatisfactory. $47.5 \%$ women were illetrate and $52.5 \%$ women were having different level of education from primary to postgraduation. 
An Indian study showed illetracy rate of $61 \%$ among study participants. ${ }^{9}$ However two local studies showed illetracy rate of $39 \%$ and $11.4 \%$ respectively. ${ }^{12,13}$ Another study by M.H.Khan done in 2007 in D.I. Khan showed illetracy rate of $1.6 \% .^{15}$

The most commonly used method in our study were interval IUCD (32.3\%) and barrier method (30.2\%). In a study by Begum KS, 33.3\% were using barrier method ${ }^{16}$ and another study done in Lucknow ${ }^{17}$ also showed that $34 \%$ couple were using barrier method for contraception. However contrasting results were shown by study in Nepal ${ }^{14}$ where preferred method of contraception were injectables. The reason of popularity of barrier method was easy availability, low cost, least side effects and protection against STDs. Most of the couples were well aware of this option. Furthermore it showed active male participation for contraception which improve the acceptance and practice of contraceptives.

The least preferred method in our study was Implanon (1.04\%). Its hormonal implant inserted subdermally in upper arm. The reason behind is limited availability and knowledge about it. Another reason was reluctance to have it inserted subdermally and fear of difficulty in removal. Although oral contraceptive pills are well known and old method of contraception but our study showed that only $8.3 \%$ women were using it. Most women thought that it is associated with weight gain. Another reason was non compliance and hence reluctance of this method. Nigar $A^{9}$ and Sohail $\mathrm{N}^{13}$ also showed low prevalence of use of OCPs in their studies.

Out of total 408 participants in our study, $53 \%(n=216)$ were not using any method of contraception and this is comparable to $58.8 \%$ nonusers in Nigar. A study. ${ }^{9}$ The etiology was multifactorial. Most common reasons were lack of knowledge (30\%) and fear of side effects (21.7\%). At this point role of print and electronic media and lady health visitors is very important. As most of our population is residing in rural areas so imparting knowledge to them is most important step in increasing contraception prevalence rate.
Another important factor among nonusers was lack of support of huaband and in laws regarding contraception. This also involved desire for a male offspring. Although women were willing for birth spacing but they lacked support from family and access to family planning services. So, again counselling of husband and family is equally important. Non cooperation from family members and husbands was also evident in other studies..$^{9,12-13}$ 9.3\% women were having religious constraint about not using any contraceptive method. One of the main hurdles to acceptance of family planning is religious beliefs which are in most cases wrongly interpreted. Here, we would like highlight the role of mass education and active involvement of religious leader and mosque muezzin to promote contraceptive practices. Fear of side effects had been reported as recurring factors for not practicing contraception in many studies. ${ }^{18}$ According to Pakistan Demographic and health Survey, 2006-2007, 10\% women were not using contraception due to fear of health issues. ${ }^{19} \mathrm{~A}$ study by Khan. AW also showed that religious barrier was main reason among nonusers. ${ }^{20}$ Another study also showed that $27 \%$ couples were not willing to use contraception owing to religious constraints. ${ }^{12}$

Complications of different methods among users were also noted in our study. Most common side effects among users were menstrual irregularity, vaginal discharge and contraceptive failure leading to conception. The results were comparable to a study done in Nepal ${ }^{14}$ showing $25.3 \%$ cases of menstrual irregularity and a local study showed $16 \%$ cases suffering from irregular menstruation. ${ }^{16}$ Weight gain was observed by $2.08 \%$ cases in our study as compared to $15 \%$ in a local study. ${ }^{16}$ In our study $38.5 \%$ users were happy with the method used and wanted to continue it. Contrasting results shown by another study where only $8.3 \%$ users were happy with method used.

Rapid population growth is a serious problem for the world especially for developing countries. Although electronic media, social media, religious scholars, healthcare professionals and government is working in collaboration to impart 
knowledge and education and for making family planning services available and acceptable to all, still contraception prevalence rate is static since many decades.

Easy access and free avaialablity of family planning services for both rural and urban areas is need of the day. As $70 \%$ population is residing in villages, so use of mobile teams and door to door family planning service provision by leady health workers is most important. All BHUs (basic health units) and RHCs (rural health centres) must have family planning services with ample availability of variety of contraceptives.

Constant motivation by ministry, health care workers, LHVs and religious scholars is needed. Counselling of family members, alleviating of fear of side effects and easy and free access to family planning services are key factors to improve contraceptive prevalence rate of Pakistan.If we want healthier and strong Pakistan to live in years to come, then effective population control should be our main aim.

\section{CONCLUSION}

There is need for strong implementation of government family planning policies and motivation of couples through media and health personnel to achieve effective use of contraceptives.

\section{RECOMMENDATIONS}

The challenges posed by a burgeoning population will be intense in future; hence meticulous family planning is the need of the hour.

1. An urgent need to reform policies pertaining to population control.

2. Creating awareness, dispelling myths; motivation through electronic and print media.

3. Involvement of the prominent individuals and clerics of the targeted population.

4. Setting up of family planning clinics at $\mathrm{BHU}$, $\mathrm{RHC}$ and district hospitals.

5. Effective counseling during antenatal period, preferably in partner's presence.

6. Earmarking time for reaffirmation in postnatal clinics

7. Training of health workers and easy accessibility to facilities

8. Involvement and availability of committed medical professionals for follow ups.

9. At secondary education, awareness should be created among students regarding the seriousness of this population explosion and its adverse effects on society.

\section{Copyright $(21$ Sep, 2020.}

\section{REFERENCES}

1. Pak Bauru of statistics -Government of Pakistan.

2. WHO: Millennium Development Goal (MDG) 5: Improve Maternal Health. 2012, 2 January 2013.

3. United Nations: Goal 5: Improving maternal health. 2012.

4. United Nations: The Millennium Development Goals Report 2015.

5. Contraceptive Performance Report 2015-2016. Government of Pakistan, Statistics Division, Pakistan Bureau of Statistics April-2017

6. The United Nations Department of Economic and Social Affairs. Trends in contraception worldwide. 2015 [Cited 2019 February 7].

7. Cahil N, Stover J, Sonneveldt E, Alkema L. Modern contraceptive use, unmet need and demand satisfied among women of reproductive age who are married or in a union in the focus countries of the family planning 2020 initiative : a systematic analysis using the family planning estimation tool. The Lancet 2018; 391: 870-83.

8. Pakistan Demographic and Health Survey 2017-18. National Institute of Population Studies, Islamabad, Pakistan.

9. Nigar.A. Contraceptive awareness and practices among rural women in Lucknow. Indian J.Obstet. Gynaecol Res.2018; 4: 454-7.

10. Weldegerima B, Denekew A. Women's knowledge, preferences, and practices of modern contraceptive methods in Woreta, Ethiopia. Res Social Adm Pharm. 2008; 4(3):302-7.

11. Palamuleni ME. Socioeconomic and demographic factors affecting contraceptive use in Malawi. African Journal of Reproductive Health 2013; 17(3 ): 91-104. 
12. Qadir S, Anbreen F, Naeem A, Akhtar MN, Shirazi SAH. Association of contraceptive barriers with socio demographic variables, Pakistan. Gomal J Med Sci 2018;16:75-8.

13. Sohail N, Shehzad F, Asad A, Ashraf S. Preference in contraception and attributing factors behind it among women presenting to family planning center in a tertiary care hospital of Pakistan. PPMJ 2015; 26 (3): $76-80$.

14. Bhandari N, Shrestha GK, Thakuri PC. Study of factors affecting contraceptive use among married women of reproductive age. JCMS 2013; 9(4): 24-29.

15. Khan $\mathrm{MH}$ et al. Study of contraceptive user women in D.I.Khan, Pakistan. Biomedica 2007; 23: 24-26.

16. Begum K.S, Alam.S, Tammama T. Changes in the contraceptive practice among the women of reproductive age in a selected hospital of Dhaka city. Med Today 2015; 27: 33-6.
17. Vasundhara Sharma, Uday Mohan, Vinita Das, and Shally Awasthi Sharma J. Socio demographic determinants and knowledge, attitude, practice: Survey of family planning. Int $\mathrm{J}$ Reprod Contracept Obstet Gynecol. 2015; 4(3):750-754.

18. Umoh AV, Abah AG. Contraception awareness and practice among antenatal attendees in Uyo, Nigeria. Pan African Med J. 2011; 10:53.

19. World Health Organization. The Family Planning Fact Sheet 2013. WHO, Geneva.

20. Khan AW, Hafeez A, Shareef R. Percieved family planning barriers in the provision of family planning services by lady health workers in Tehsil Gujar Khan. J Pak Med Assoc 2012; 62:1318-21

\begin{tabular}{|c|c|c|c|}
\hline \multicolumn{4}{|c|}{ AUTHORSHIP AND CONTRIBUTION DECLARATION } \\
\hline Sr. \# & Author(s) Full Name & Contribution to the paper & Author(s) Signature \\
\hline 1 & $\begin{array}{l}\text { Naheed Jmal Faruqi } \\
\text { Drakhshan Nauman }\end{array}$ & $\begin{array}{l}\text { Study design + compilation } \\
\text { of data. } \\
\text { Manuscript writing and } \\
\text { literature review. }\end{array}$ & \\
\hline 3 & Nadia Saif & Data analysis. & Nadia \\
\hline 4 & Shereen Sukhan & Data collection. & Sheseen Sukinam \\
\hline 5 & Faiza Saghir & Data collection \& calculation. & taite. \\
\hline 6 & Fariha Farooq & Final review of article. & Howere \\
\hline
\end{tabular}

